\title{
A novel diblock copolymer of (monomethoxy poly [ethylene glycol]-oleate) with a small hydrophobic fraction to make stable micelles/polymersomes for curcumin delivery to cancer cells
}

\author{
This article was published in the following Dove Press journal: \\ International Journal of Nanomedicine \\ 28 November 2014 \\ Number of times this article has been viewed
}

\author{
Vahid Erfani-Moghadam ${ }^{1,6}$ \\ Alireza Nomani ${ }^{2}$ \\ Mina Zamani ${ }^{3}$ \\ Yaghoub Yazdani ${ }^{4}$ \\ Farhood Najafi ${ }^{5}$ \\ Majid Sadeghizadeh ${ }^{1,3}$ \\ 'Department of Nanobiotechnology, \\ Faculty of Biological Sciences, \\ Tarbiat Modares University, \\ Tehran, Iran; ${ }^{2}$ Department of \\ Pharmaceutics, Faculty of Pharmacy, \\ Zanjan University of Medical \\ Sciences, Zanjan, Iran; ${ }^{3}$ Department \\ of Genetics, Faculty of Biological \\ Sciences, Tarbiat Modares University, \\ Tehran, Iran; ${ }^{4}$ Infectious Diseases \\ Research Center and Laboratory \\ Science Research Center, Golestan \\ University of Medical Sciences, \\ Gorgan, Golestan, Iran; ${ }^{5}$ Department \\ of Resin and Additives, Institute for \\ Color Science and Technology, Tehran, \\ Iran; ${ }^{6}$ Department of Biotechnology, \\ Faculty of Advanced Medical \\ Technology, Golestan University \\ of Medical Sciences, Gorgan, Iran
}

Correspondence: Majid Sadeghizadeh Department of Genetics, Faculty of Biological Sciences, Tarbiat Modares University, Tehran, I4II5-I54, Iran Fax +98 2I 82884484

Email sadeghma@modares.ac.ir

Alireza Nomani

Department of Pharmaceutics, Faculty of Pharmacy, Zanjan University of Medical Sciences, Zanjan, 56I84 45I39, Iran

Tel +98 24I 4273639

Fax +98 24I 4273639

Email arnomani@zums.ac.ir

\begin{abstract}
Curcumin is a potent natural anticancer agent, but its effectiveness is limited by properties such as very low solubility, high rate of degradation, and low rate of absorption of its hydrophobic molecules in vivo. To date, various nanocarriers have been used to improve the bioavailability of this hydrophobic biomaterial. This study investigates the encapsulation of curcumin in a novel nanostructure of monomethoxy poly(ethylene glycol)-oleate (mPEG-OA) and its anticancer effect. Tests were done to determine the critical micelle concentration (CMC), encapsulation efficiency, drug-loading efficiency, and cytotoxicity (against U87MG brain carcinoma cells and HFSF-PI3 cells as normal human fibroblasts) of some nanodevice preparations. The results of fluorescence microscopy and cell-cycle analyses indicated that the in vitro bioavailability of the encapsulated curcumin was significantly greater than that of free curcumin. Cytotoxicity evaluations showed that half maximal inhibitory concentrations of free curcumin and curcumin-loaded mPEG-OA for the U87MG cancer cell line were $48 \mu \mathrm{M}$ and $24 \mu \mathrm{M}$, respectively. The Annexin-V-FLUOS assay was used to quantify the apoptotic effect of the prepared nanostructures. Apoptosis induction was observed in a dose-dependent manner after curcumin-loaded mPEG-OA treatments. Two common self-assembling structures, micelles and polymersomes, were observed by atomic force microscopy and dynamic light scattering, and the abundance of each structure was dependent on the concentration of the diblock copolymer. The mPEG-OA micelles had a very low CMC (13.24 $\mu \mathrm{M}$ or $0.03 \mathrm{~g} / \mathrm{L})$. Moreover, atomic force microscopy and dynamic light scattering showed that the curcumin-loaded mPEG-OA polymersomes had very stable structures, and at concentrations 1,000 times less than the CMC, at which the micelles disappear, polymersomes were the dominant structures in the dispersion with a reduced size distribution below $150 \mathrm{~nm}$. Overall, the results from these tests revealed that this nanocarrier can be considered as an appropriate drug delivery system for delivering curcumin to cancer cells.
\end{abstract}

Keywords: anticancer agent, nanocarrier, encapsulation, bioavailability, apoptosis, critical micelle concentration

\section{Introduction}

Extensive and detailed investigations have been made in recent decades on cancer treatments, but cancer still remains a leading cause of many deaths worldwide. ${ }^{1}$ Chemotherapeutic strategies used to treat cancer commonly target a specific pathway and are effective for shrinking tumor size, but are often not able to completely destroy a tumor or prevent its recurrence. In addition, these strategies usually are not effective against resistant tumor cells. It is, therefore, important that a candidate anticancer agent be able 
to target multiple cellular signaling pathways with the lowest possible toxicity to normal cells. Of these anticancer agents, natural products and extracts have shown good potential and results. ${ }^{2}$ Curcumin is derived from turmeric (Curcuma longa). It is a natural extract and as such represents a good candidate for anticancer treatment. Traditionally, turmeric and its derivatives have been used extensively in Eastern countries as a food additive and for various medicinal purposes. In recent decades, several researchers have reported the anticancer effect of curcumin..$^{3-5}$ The effect of curcumin on cancer cells was found to be related to multiple cellsignaling pathways and prevention of the processes of cell proliferation, invasion, metastasis, and angiogenesis. However, some properties of curcumin such as very low water solubility and bioavailability hamper its suitability for use in cancer therapy. In this regard, the application of nanocarriers represents a good solution for curcumin delivery to cancer cells. An extensive review on curcumin nanoformulations has been published by Yallapu et al. ${ }^{2}$

Much research has been published recently on polymeric micelles as a strategy for drug delivery. ${ }^{6,7}$ Amphiphilic block copolymers can self-assemble in an aqueous solution to form micellar structures. The hydrophilic surface layers of micelles may consist of polyethylene glycol (PEG) chains that can hinder the interaction between hydrophobic compartments and biological membranes, and prevent adsorption of plasma proteins onto nanoparticle surfaces. This effect significantly reduces nanoparticle recognition and elimination by the immune system. ${ }^{8}$

Different kinds of high-molecular weight amphiphilic block copolymers have been utilized to form polymersomes. Polymersomes generally have a thick and versatile membrane. The physical and chemical properties of polymersomes can be tuned by using various and appropriate block lengths and chemical structures. Manipulating the elasticity and permeability of polymersome membranes can produce high stability in comparison to liposomes and simple lipidbased vesicles formed by low-molecular weight surfactants and lipids. ${ }^{7,9,10}$ Furthermore, as a general rule, it is now clearly evident that amphiphilic block copolymers can form vesicles (polymersomes) at the hydrophilic domain to a total mass ratio $(f)$ of about $35 \% \pm 10 \% .^{11}$

Previous studies by our group have demonstrated that curcumin encapsulated in dendrosome, a diblock nanostructure made of oleic acid and PEG (400 Da), can kill cancer cells through the apoptosis pathway and significantly reduce tumor size in mice. ${ }^{12,13}$ In the present study, the dendrosome structure applied was modified in order to obtain better thermodynamic stability. This modification was made by using monomethoxy
PEG (mPEG) of a higher molecular weight (mol wt) of 2,000 $\mathrm{Da}$, and the self-assembled structures were used as the encapsulating structures for curcumin. According to our results, based on measurements of critical micelle concentration (CMC), calculated loading and encapsulation efficiencies, and results of other performed cellular experiments, this novel small, hydrophobic fraction copolymer $(f \approx 85 \%)$ vesicular nanocarrier can be considered an appropriate drug delivery system for curcumin delivery to cancer cells.

\section{Methods \\ Materials}

Curcumin, pyrene, triethyl amine, and chloroform were purchased from EMD Millipore (Billerica, MA, USA). Oleoyl chloride and mPEG (mol wt 2,000 Da) were purchased from Sigma-Aldrich Co., (St Louis, MO, USA). The Annexin-V-FLUOS/propidium iodide (PI) staining kit was purchased from Hoffman-La Roche Ltd., (Basel, Switzerland). All materials were used as received without any further purification. All solvents used in tests were of analytical grade and obtained from EMD Millipore.

\section{Synthesis of mPEG-OA conjugate}

The mPEG-oleate (OA) was synthesized by esterification of oleoyl chloride (3.01 g, $0.01 \mathrm{~mol}$ ) and methoxy PEG 2,000 $(20 \mathrm{~g}, 0.01 \mathrm{~mol})$ in the presence of triethyl amine $(1.2 \mathrm{~g}$, $0.012 \mathrm{~mol}$ ) and chloroform as the solvent, at $25^{\circ} \mathrm{C}$ for 2 hours. The conjugate was characterized by proton nuclear magnetic resonance imaging ( $\left.{ }^{1} \mathrm{H} \mathrm{NMR}\right)$ (spectra were recorded in dimethyl sulfoxide [DMSO] on a Bruker DRX $400 \mathrm{MHz}$ apparatus; Bruker Optik GmbH, Ettlingen, Germany) and Fourier transform infrared (FT-IR) spectroscopic analyses (PerkinElmer Inc., Waltham, MA, USA).

\section{Determination of CMC}

The CMC of mPEG-OA was determined by the pyrene fluorescence absorbance spectral shift as described by Sahu et al. ${ }^{14}$ First, $3 \mathrm{~mL}$ of a pyrene solution $\left(10^{-6} \mathrm{M}\right)$ in acetone was poured into a glass test tube, and then the solvent was removed. Next, $5 \mathrm{~mL}$ of various concentrations of mPEG-OA copolymer in phosphate buffered saline (PBS) (0.01 M, pH 7.4), ranging from $0.005-1 \mathrm{mg} / \mathrm{mL}$, was added to prepare the final pyrene solution of $6.0 \times 10^{-7} \mathrm{M}$. The evaluation was made for the fluorescence spectra of pyrene (300-350 nm for excitation, with slit widths of $2.5 \mathrm{~nm}$ at an emission wavelength of $390 \mathrm{~nm}$ with slit widths of $5.0 \mathrm{~nm}$ ). The fluorescence excitation shifts within the range of 334-339 nm were used to determine the CMC of mPEG-OA nanocarriers (PerkinElmer fluorimeter). 


\section{Physical properties of particles: size, morphology, and zeta potential}

Dynamic light scattering (DLS) and atomic force microscopy (AFM) studies were performed to determine the physical properties of the mPEG-OA nanocarriers. The zeta potential, size, and polydispersity index (PDI) of curcumin/mPEG-OA (Cur/mPEG-OA) nanocarriers in PBS (0.01 M, pH 7.4) were analyzed by DLS (Zetasizer Nano ZS; Malvern Instruments, Malvern, UK) using an argon laser beam at $633 \mathrm{~nm}$ and a $90^{\circ}$ scattering angle. The shape of the nanocarriers was characterized by AFM (JPK Instruments AG, Berlin, Germany), as described by Darvishi et al. ${ }^{15}$

\section{Curcumin encapsulation efficiency and drug-loading content}

The encapsulation efficiency (EE) and drug-loading (DL) of curcumin were measured as described by Gou et al. ${ }^{16}$ Curcumin (0 mg, $2 \mathrm{mg}, 4 \mathrm{mg}, 6 \mathrm{mg}, 8 \mathrm{mg}, 12 \mathrm{mg}, 16 \mathrm{mg}, 20 \mathrm{mg}$, and 25 $\mathrm{mg}$ ) and $\mathrm{mPEG}-\mathrm{OA}$ copolymer $(100 \mathrm{mg})$ were codissolved in $3 \mathrm{~mL}$ of acetone in different glass tubes. Then, $3 \mathrm{~mL}$ of water was added to each tube with constant stirring. Next, the acetone was evaporated using two methods: rotary evaporation (45 minutes) and overnight incubation in a shaker at $37^{\circ} \mathrm{C}$. After that, samples were filtered using a syringe filter (pore size: $0.22 \mu \mathrm{m}$ ) (Jet Bio-Filtration Products, Co., Ltd., Guangzhou, People's Republic of China) to remove any undissolved curcumin. Each of the prepared solutions was lyophilized, and then $10 \mathrm{mg}$ of lyophilized Cur/mPEG-OA nanocarrier was dissolved in $1 \mathrm{~mL}$ of methanol. Samples were then shaken vigorously for 2 minutes followed by 10 minutes of sonication in an ultrasonic water bath for disruption of the nanocarrier structures. The amount of curcumin in the solution was quantified spectrophotometrically at $425 \mathrm{~nm}\left(\right.$ NanoDrop $^{\circledR} \mathrm{UV}-\mathrm{Vis}$ spectrophotometer; Thermo Fisher Scientific, Waltham, MA, USA). Finally, evaluations were made for the DL and EE of Cur/mPEG-OA according to the following equations:

$$
\begin{aligned}
& \mathrm{EE}(\%)=\frac{\text { Weight of curcumin in nanocarrier }}{\text { Weight of feeding curcumin }} \times 100 \\
& \mathrm{DL}(\%)=\frac{\text { Weight of curcumin in nanocarrier }}{\text { Weight of total nanocarrier }} \times 100
\end{aligned}
$$

\section{Nanostructure stability assay}

Different samples of Cur/mPEG-OA aqueous dispersions were maintained separately at $4^{\circ} \mathrm{C}$ and room temperature for durations of 24 hours and 6 months. The stability of each dispersion was examined by the naked eye and DLS.
Any precipitation was regarded as instability. ${ }^{16}$ Moreover, the lyophilized samples were redissolved in water by simple manual shaking, and then evaluations of particle size and size distribution were carried out by DLS. ${ }^{17}$

\section{In vitro cytotoxicity}

The U87 human glioblastoma cell line (U87MG) and human normal fibroblastic cells (HFSF-PI3) were obtained from the Pasteur Institute (Tehran, Iran) and cultured in Gibco ${ }^{\circledR}$ Roswell Park Memorial Institute (RPMI) 1640 medium and Gibco $^{\circledR}$ high-glucose Dulbecco’s Modified Eagle’s Medium (Thermo Fisher Scientific), respectively. Media were supplemented with $10 \% \mathrm{v} / \mathrm{v}$ fetal bovine serum, $1 \% \mathrm{~L}$-glutamine, and $1 \%$ penicillin/streptomycin (all purchased from Thermo Fisher Scientific). All cells were maintained at $37^{\circ} \mathrm{C}$ in a humidified $5 \% \mathrm{CO}_{2}$ atmosphere.

The cellular toxicity of nanocarriers was assessed using the 3-(4,5-dimethylthiazol-2-yl)-2,5-diphenyltetrazolium bromide (MTT) assay (Sigma-Aldrich Co.) according to the manufacturer's instructions. Briefly, U87MG cells $\left(1 \times 10^{4}\right.$ cells/well $)$ and HFSF-PI3 cells $\left(1.5 \times 10^{4}\right.$ cells/well $)$ were seeded in 96-well plates. Twenty-four hours after cell seeding, cells were treated with different concentrations (0-50 $\mu \mathrm{M}$ for U87MG and $0-100 \mu \mathrm{M}$ for HFSF-PI3 cells) of free curcumin, mPEG-OA-encapsulated curcumin, and void mPEG-OA nanocarriers. Curcumin stock solution $(100 \mu \mathrm{M})$ in DMEM was prepared from $10 \mathrm{mM}$ curcumin in methanol. The methanol percentage in the final solutions was kept lower than $0.4 \% \mathrm{v} / \mathrm{v}$. After incubation periods of 24 hours and 48 hours, media containing the treatment agents were carefully removed and $20 \mu \mathrm{L}$ medium containing $5 \mathrm{mg} / \mathrm{mL}$ MTT in PBS was added to each well. After 4 hours at $37^{\circ} \mathrm{C}$, the medium was gently removed and $200 \mu \mathrm{L}$ DMSO was added to each well. The absorbance, which was proportional to the cell viability, was subsequently measured at $490 \mathrm{~nm}$ in each well using an enzyme-linked immunosorbent assay plate reader. All values were compared to the corresponding controls. Cell viability was calculated as the percentage of cell viability of treated cells relative to that of the control cells.

\section{Fluorescence microscopy and cell-cycle analysis}

Fluorescence microscopy and flow cytometry were applied to evaluate the uptake of curcumin or curcumin nanocarriers in U87MG cells. For both fluorescence microscopic and cellcycle analyses, $10^{5} \mathrm{U} 87 \mathrm{MG}$ cells were seeded in 12-well plates 24 hours prior to the treatment, and cells were treated with $30 \mu \mathrm{M}$ curcumin, void nanocarriers, or $22 \mu \mathrm{M}$ Cur/mPEG-OA, 
while the cells were incubated at $37^{\circ} \mathrm{C}$ in a humidified $5 \%$ $\mathrm{CO}_{2}$ incubator. After treatment, the cells were subjected to visual evaluation by fluorescence microscopy (Nikon Corporation, Tokyo, Japan) based upon the intrinsic fluorescence of curcumin. For this, after 4 hours of treatment and two gentle washes with PBS, cells were subjected to visual evaluation (fluorescence microscopy; Nikon Corporation) of cell uptake. For cell-cycle analyses, the medium was first replaced with fresh media containing the mentioned concentrations of curcumin, void nanocarriers, or Cur/mPEG-OA. After incubation for 24 hours, cells were collected, washed twice with cold PBS, and fixed with ice-cold $70 \%$ ethanol at $4{ }^{\circ} \mathrm{C}$ overnight. After washing twice with cold PBS, cells were resuspended in PBS containing $50 \mu \mathrm{g} / \mathrm{mL}$ of PI, $0.1 \%$ sodium citrate, and 0.1 Triton $\mathrm{X}-100$ followed by shaking at $37^{\circ} \mathrm{C}$ for 15 minutes. The DNA content of the samples was analyzed using a flow cytometer (BD FACSCanto ${ }^{\mathrm{TM}}$ II; BD Biosciences, San Jose, CA, USA).${ }^{18}$ For flow cytometric and cell-cycle analyses, at least 10,000 events were counted for each measurement, and data were evaluated using Flowing Software 2.5.1 (Turku Centre for Biotechnology, University of Turku, Turku, Finland). The percentages of cells in each phase of the cell cycle were determined from the results of three tests and expressed as means \pm standard deviations. Means were compared using the least significant difference test $(P<0.05)$ by SAS software (version 9.1; SAS Institute Inc., Cary, NC, USA).

\section{Apoptosis detection}

The apoptotic index of each sample was measured through flow cytometric assays using Annexin-V-FLUOS and PI staining kits (Hoffman-La Roche Ltd.) according to the manufacturer's instructions. Briefly, U87MG cells were seeded $\left(0.3 \times 10^{6}\right.$ cells/well $)$ into six-well plates and allowed to adhere overnight before treatment with the desired concentrations of Cur/mPEG-OA or blank mPEG-OA for 24 hours. Trypsindigested cells were centrifuged at $200 \times g$ for 5 minutes. The cell pellet was resuspended in $100 \mu \mathrm{L}$ of Annexin-V-FLUOS labeling solution, incubated for $10-15$ minutes at $15^{\circ} \mathrm{C}-20^{\circ} \mathrm{C}$, and immediately analyzed using a CyFlow Space Flow Cytometer (Partec GmbH, Münster, Germany). The data were evaluated using FSC Express Software version 4.07 (Demo Version of Research Edition; De Novo Software, Glendale, CA, USA).

\section{Results and discussion FT-IR and NMR assays}

The synthesis of mPEG-OA diblock monomers was confirmed by FT-IR (Figure 1) and NMR (Figure 2) spectroscopy. Figure 1 shows the FT-IR spectrum of freeze-dried powder of synthesized mPEG-OA. It demonstrates the stretching bands of C-H aliphatic at 2,889 $\mathrm{cm}^{-1}, 2,947 \mathrm{~cm}^{-1}$, and $2,960 \mathrm{~cm}^{-1}$. The $\mathrm{C}-\mathrm{H}$ bending vibration of $\mathrm{CH}_{2}$ and $\mathrm{C}-\mathrm{H}$ bending vibration of $\mathrm{CH}_{3}$ were determined at $1,467 \mathrm{~cm}^{-1}$ and $1,343 \mathrm{~cm}^{-1}$, respectively. The broad band C-O stretching vibration was evident at $1,112 \mathrm{~cm}^{-1}$, and the signal at $1,736 \mathrm{~cm}^{-1}$ showed the $\mathrm{C}=\mathrm{O}$ stretching vibration of ester bands between oleic acid and $\mathrm{mPEG}$.

Figure 2 shows the ${ }^{1} \mathrm{H}$ NMR spectrum of $\mathrm{mPEG}-\mathrm{OA}$ dissolved in DMSO- $\mathrm{d}_{5}$. The saturated proton signals of fatty ester were obvious at $0.8 \mathrm{ppm}, 1.2 \mathrm{ppm}, 1.5 \mathrm{ppm}, 2 \mathrm{ppm}$, and $2.3 \mathrm{ppm}$. The residual DMSO- $\mathrm{d}_{5}$ signal was at $2.5 \mathrm{ppm}$. The DMSO- $\mathrm{d}_{5}$ water impurity was observed at $3.3 \mathrm{ppm}$ as a broad band. The $\mathrm{CH}_{3}$ protons of $\mathrm{mPEG}$ were identified at $3.2 \mathrm{ppm}$. The multiplet signals at $3.5 \mathrm{ppm}$ were related to the $\mathrm{CH}_{2}$ protons of ethylene oxide units of mPEG. The $\mathrm{CH}_{2}$ protons of ethylene oxide of mPEG connected to fatty acid were detected at $4.1 \mathrm{ppm}$ and $4.2 \mathrm{ppm}$. Unsaturated protons of oleate were present at $5.3 \mathrm{ppm}$. All of these FT-IR and ${ }^{1} \mathrm{H}$ NMR findings indicate that the mPEG-OA structure was correct and the synthesis was carried out properly.

\section{CMC of nanocarriers}

From the crossover point in Figure 3, the $\mathrm{CMC}$ of nanocarriers was determined to be $13.24 \mu \mathrm{M}(0.03 \mathrm{~g} / \mathrm{L})$, which is much lower than the $\mathrm{CMC}$ of common low-molecular weight surfactants such as $2.3 \mathrm{~g} / \mathrm{L}$ for sodium lauryl sulphate in water. It is four times lower than the CMC of mPEG-palmitate copolymers, which has been reported to be $53.3 \mu \mathrm{M}(0.12 \mathrm{~g} / \mathrm{L}) .{ }^{14}$ Such a low value of CMC for mPEG-OA implies the latent thermodynamic stability of micelles and may increase the

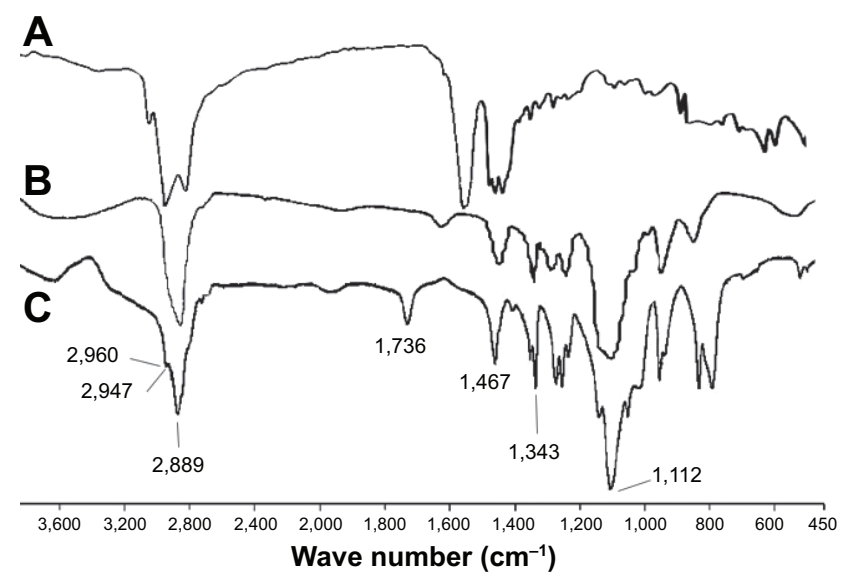

Figure I Fourier transform infrared spectra of mPEG-OA nanocarriers. Notes: (A) OA, (B) mPEG, and (C) mPEG-OA nanocarriers as a freeze-dried powder. The peak at $1,736 \mathrm{~cm}^{-1}$ shows the esteric bond between OA and mPEG. Abbreviations: mPEG-OA, monomethoxy poly(ethylene glycol)-oleate; OA, oleic acid; mPEG, monomethoxy poly(ethylene glycol). 

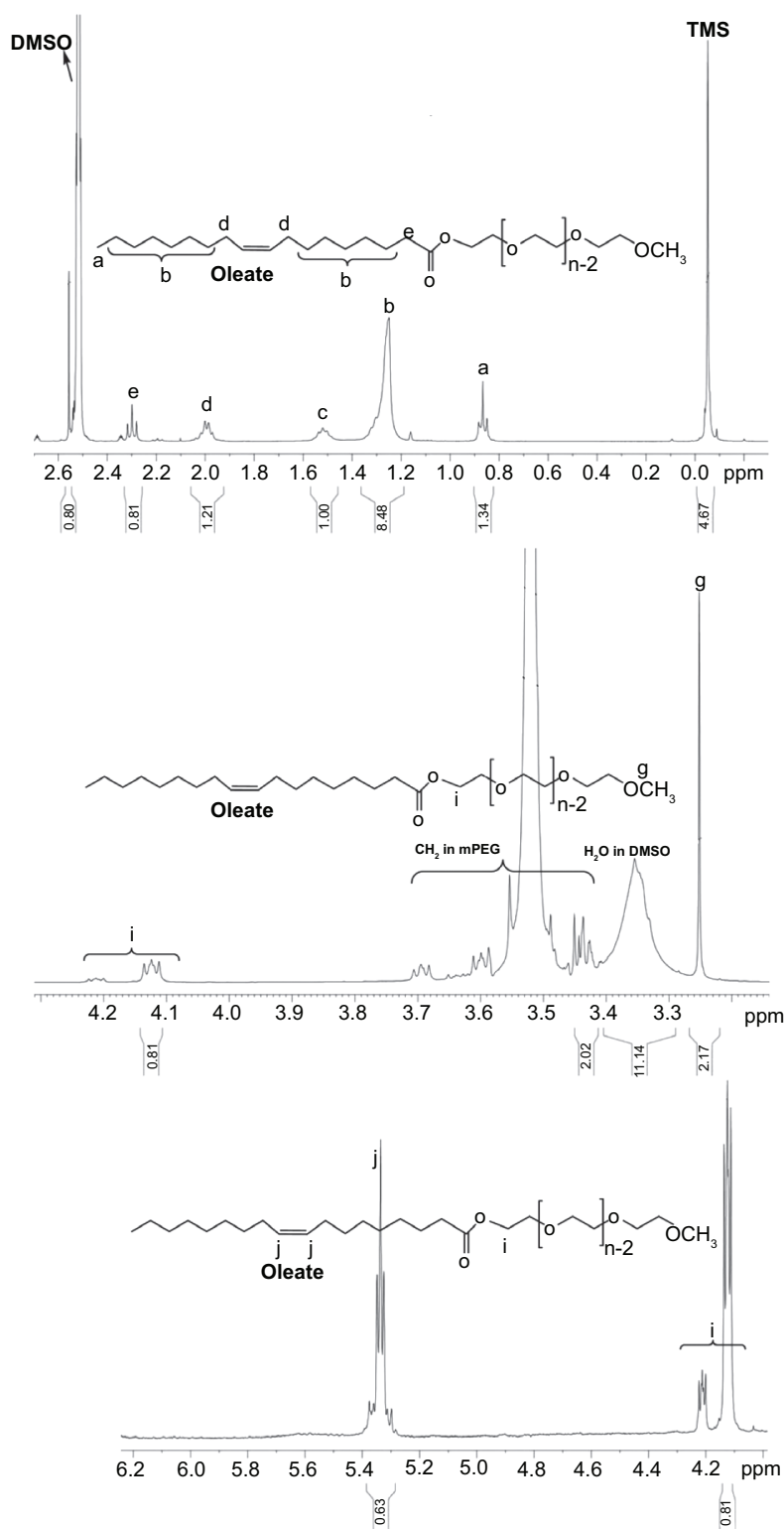

Figure 2 ' $\mathrm{H}$ NMR spectrum of mPEG-OA in DMSO- $\mathrm{d}_{5}$.

Notes: The saturated protons in fatty ester were observed at $0.8 \mathrm{ppm}, 1.2 \mathrm{ppm}$, I.5 ppm, $2 \mathrm{ppm}$, and $2.3 \mathrm{ppm}$. The $\mathrm{CH}_{3}$ protons of mPEG were at $3.2 \mathrm{ppm}$. The $\mathrm{CH}_{2}$ protons of ethylene oxide units of mPEG were observed as multipeaks at $3.5 \mathrm{ppm}$. The $\mathrm{CH}_{2}$ protons of ethylene oxide of mPEG connected to fatty acid chloride were at $4.1 \mathrm{ppm}$ and $4.2 \mathrm{ppm}$. Unsaturated protons of oleate were at $5.3 \mathrm{ppm}$.

Abbreviations: DMSO, dimethyl sulfoxide; 'H NMR, proton nuclear magnetic resonance; mPEG-OA, monomethoxy poly(ethylene glycol)-oleate; mPEG, monomethoxy poly(ethylene glycol); TMS, tetrametylsilane.

stability of the micelles after in vivo dilution. This may result in an enhanced blood circulation time of the prepared nanostructures, which usually is favorable for drug delivery and tumor tissue targeting. ${ }^{14,19}$

\section{Encapsulation and DL efficiencies}

Various amounts of curcumin (from 2-25 mg) were loaded into $100 \mathrm{mg}$ mPEG-OA nanocarriers in dispersion. The soluble Cur/mPEG-OA complexes were filtered through a $0.22 \mu \mathrm{m}$
A

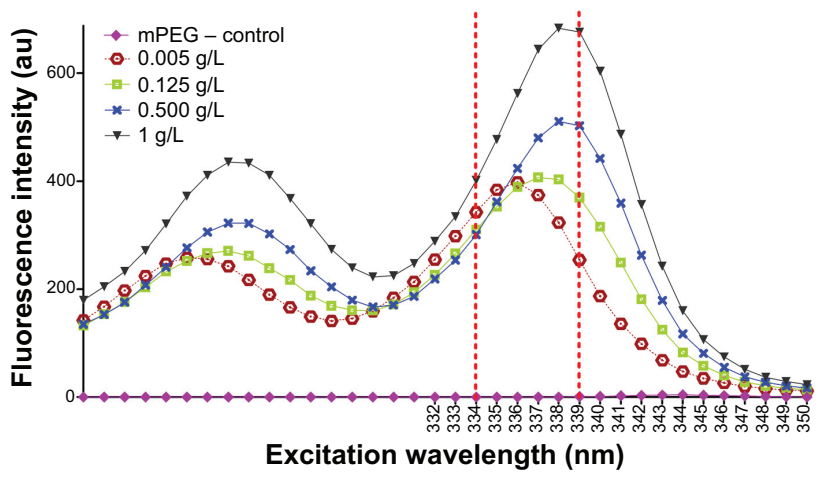

B

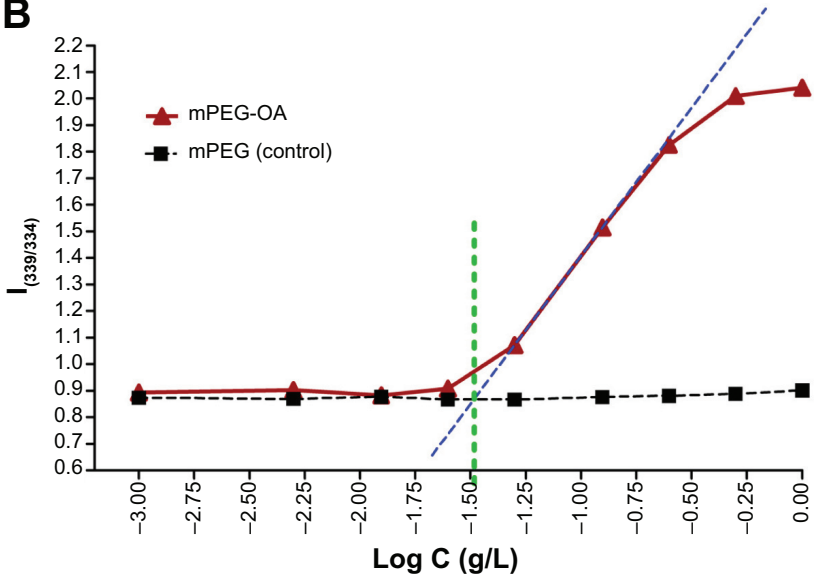

Figure 3 Determination of CMC of mPEG-OA.

Notes: (A) Four datasets from ten are displayed to simply show the fluorescence excitation intensity below and above the CMC when micelles develop. (B) CMC obtained from the crossover point, where $C$ is the concentration of nanocarrier. Abbreviations: mPEG, monomethoxy poly(ethylene glycol); CMC, critical micelle concentration; mPEG-OA, monomethoxy poly(ethylene glycol)-oleate.

filter in order to remove any insoluble curcumin. The filtrate obtained was freeze-dried to obtain solid complexes, and then drug encapsulation was confirmed by FT-IR spectroscopy of the freeze-dried samples (Figure 4). Curcumin shows a carbonyl band at $1,628 \mathrm{~cm}^{-1}$, and we can see this band in curcumin-encapsulating mPEG-OA (freeze-dried powder), a physical mixture of the void mPEG-OA nanocarriers and free curcumin. The presence of bands at $1,628 \mathrm{~cm}^{-1}$ and $1,736 \mathrm{~cm}^{-1}$ in the Cur/mPEG-OA spectrum provided evidence that the encapsulation took place appropriately.

The EE (Figure 5A) and DL (Figure 5B) were determined to be $87.1 \% \pm 7.7 \%$ and $5.22 \% \pm 0.46 \%$, respectively, for the ratio of $0.06 \%$ (curcumin:mPEG-OA w/w). The EE for mPEG-palmitate at a $0.05 \% \mathrm{w} / \mathrm{w}$ ratio (curcumin:nanocarrier) was reported to be about $30 \% .{ }^{14}$ However, in this study, the EE of curcumin:nanocarrier w/w ratio of $0.06 \%$ was significantly higher (EE of more than $80 \%$ ). Moreover, although it seems that the amount of $8.8 \%$ is the maximum achieved 


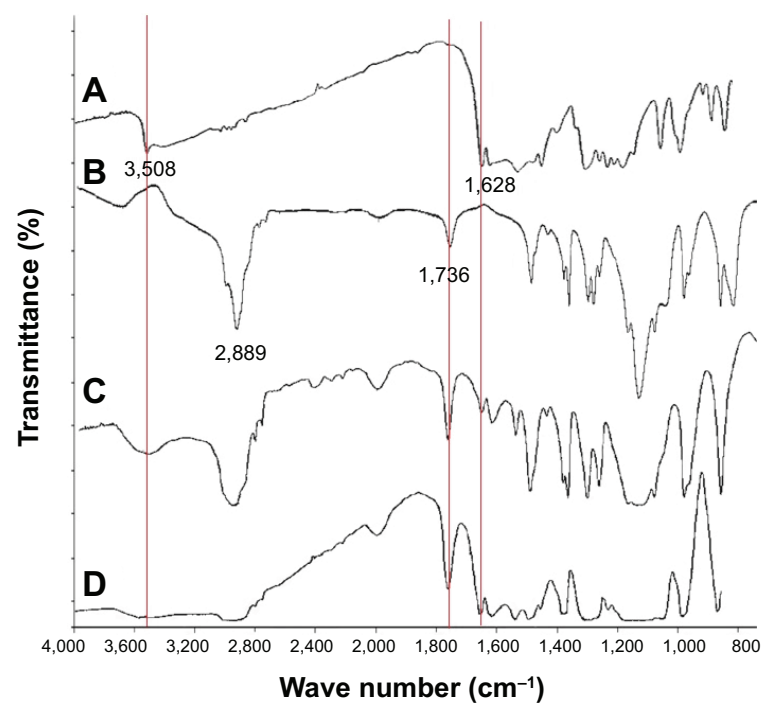

Figure 4 Fourier transform infrared spectra of curcumin, void mPEG-OA nanocarriers, curcumin encapsulated in mPEG-OA nanocarrier, and a physical mixture of curcumin with void mPEG-OA nanocarriers.

Notes: (A) Curcumin, (B) void mPEG-OA nanocarriers, (C) Cur/mPEG-OA (encapsulated curcumin) as a freeze-dried powder, and (D) physical mixture of curcumin and void mPEG-OA nanocarriers.

Abbreviations: mPEG-OA, monomethoxy poly(ethylene glycol)-oleate; Cur/ $\mathrm{mPEG}-\mathrm{OA}$, curcumin/monomethoxy poly(ethylene glycol)-oleate.

DL (Figure 5), the DL of 6\% was found to be more stable than that of $8 \%$. This was revealed by the incubation of the samples for 24 hours at $4^{\circ} \mathrm{C}$; after this incubation time, some curcumin precipitation was observed in samples with a DL greater than $8 \%$. These results indicated that the curcumin:nanocarrier $\mathrm{w} / \mathrm{w}$ ratio of $0.06 \%$ was an appropriate ratio for the following experiments.

\section{Physical properties of particles: size, morphology, and zeta potential}

Evaluations of size, zeta potential, and morphology of the nanocarriers were determined by DLS and AFM, and the results are presented in Figure 6 and Table 1. Generally, the results showed that $\mathrm{mPEG}-\mathrm{OA}$ had two particle forms, micelles and polymersomes, both of which were spherical in shape. The DLS results showed that the mean size of the micelles was $18.33 \pm 5.32 \mathrm{~nm}$ and that of the polymersomes was $99.4 \pm 65 \mathrm{~nm}$.

Interestingly, according to Figure 6, the DLS data showed a relative monodispersity of $\mathrm{mPEG}-\mathrm{OA}$ nanocarriers when they were stored for 1 week at room temperature (mean PDI $=0.182 \pm 0.072$ with $100 \%$ polymersomes with a mean size of $100 \pm 42.6 \mathrm{~nm})$. However, the DLS and AFM results revealed that the curcumin-loaded $\mathrm{mPEG}-\mathrm{OA}$ polymersomes could be observed even when the concentration of copolymer was 1,000 -fold below that of CMC (13.24 nM or $\left.3 \times 10^{-5} \mathrm{~g} / \mathrm{L}\right)$. Although the populations of both forms of particles (ie, micelles and polymersomes) increased at the higher concentrations, the increase in the micellar form appears to have been more than that of polymersomes (Figure 7 and Table 1). At concentrations lower than the CMC, the population of polymersomes decreased less than that of micelles, which means that this form was stable even at concentrations much lower than the CMC. Pearson et $\mathrm{al}^{20}$ reported that, in general, micelles are thermodynamically unstable and that they tend to join together and form polymersomes, which are more stable than micelles.

The negative zeta potential of mPEG-OA nanostructures $(-32.6 \pm 11.1 \mathrm{mV})$ induced by oleate blocks in the copolymer structure seems to be adequate for particle stability and uniform size distribution.

There is a significant difference between the dynamics of micelle and vesicle formation/breakdown. Micelles can form quite quickly - that is, in less than a second for most micellar systems. For vesicles of synthetic surfactants, this
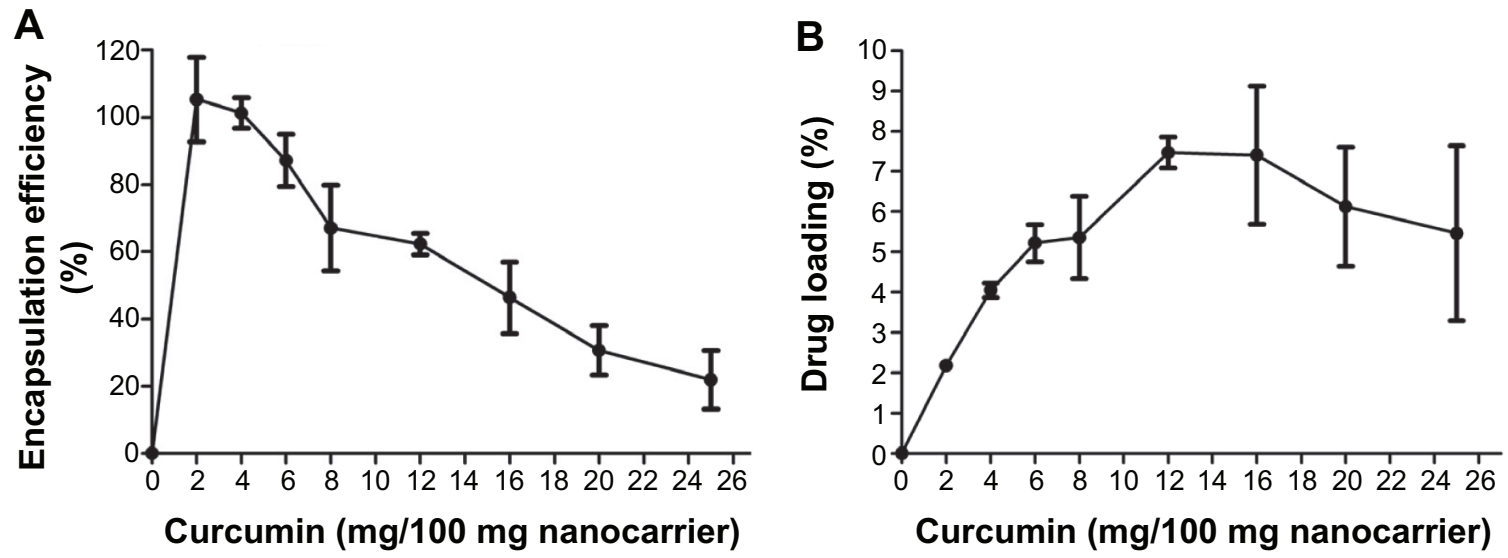

Figure $5 \mathrm{EE}$ and loading efficiency of curcumin in mPEG-OA nanocarriers.

Notes: (A) EE and (B) curcumin loading efficiency.

Abbreviations: EE, encapsulation efficiency; mPEG-OA, monomethoxy poly(ethylene glycol)-oleate. 


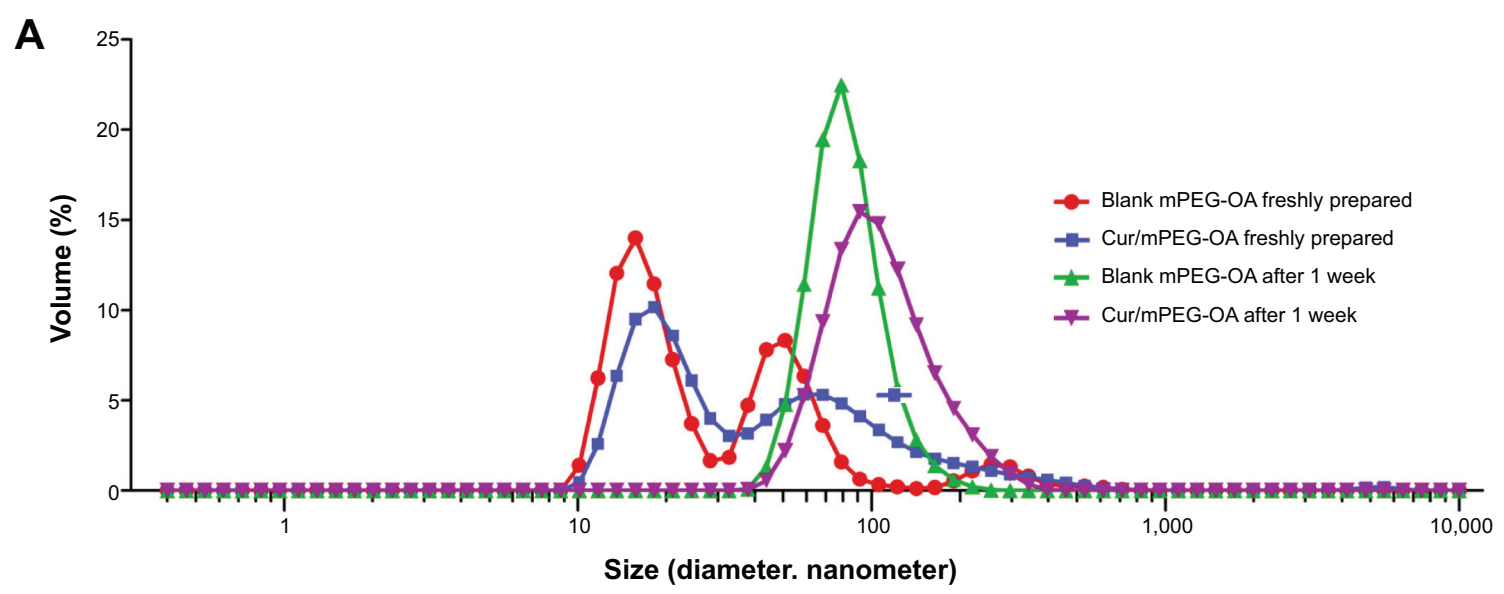

B

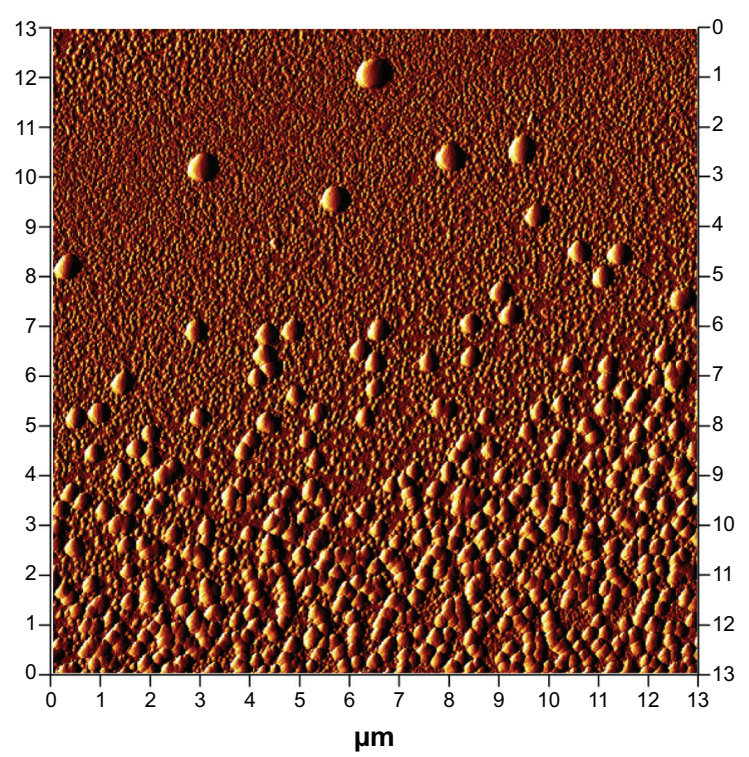

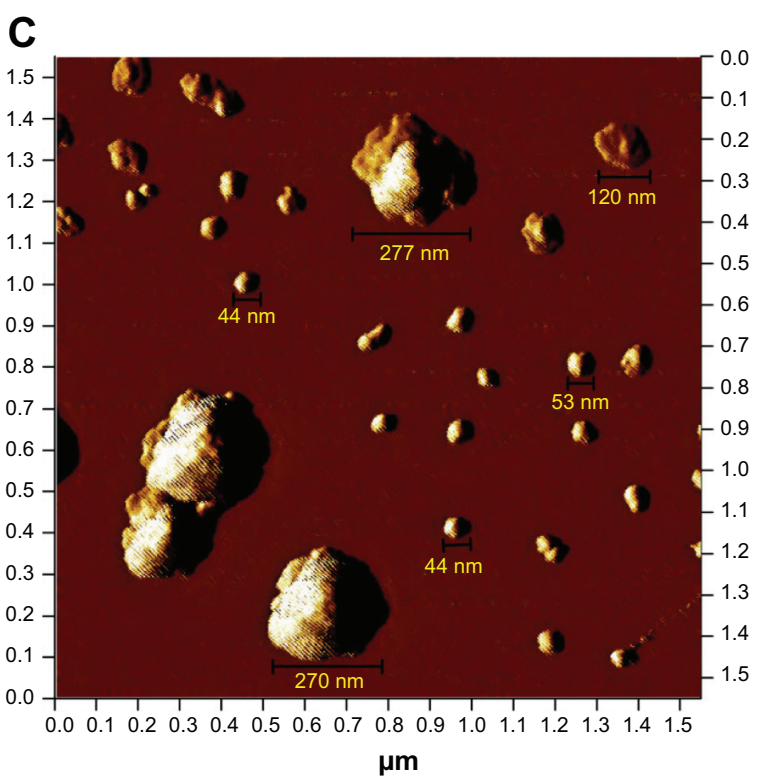

$\mu \mathrm{m}$

Figure 6 Morphology and particle size distribution of Cur/mPEG-OA nanocarriers analyzed by AFM and DLS methods.

Notes: (A) DLS diagram for fresh samples and those after I week at room temperature. (B) AFM image of Cur/mPEG-OA nanocarriers redissolved in water after freeze-

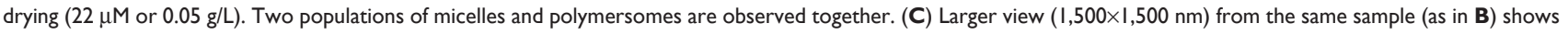
the sizes of mPEG-OA particles.

Abbreviations: mPEG-OA, monomethoxy poly(ethylene glycol)-oleate; Cur/mPEG-OA, curcumin/monomethoxy poly(ethylene glycol)-oleate; AFM, atomic force microscopy; DLS, dynamic light scattering.

formation needs a time duration of several seconds to a minute, although a millisecond time period is just enough for surfactant monomer exchange between vesicles and aqueous solution. ${ }^{21}$ Pearson et al ${ }^{20}$ also described some examples of micelle-to-vesicle transition according to block length and hydrophilic content that leads to the formation of intermediate structures such as "jellyfish" and "octopus" aggregates, which are precursors to polymersomes. Zana ${ }^{22}$ reported that micelles constantly form and break down in solution, and at a very low concentration close to the $\mathrm{CMC}$, surfactants start forming micelles that may turn into vesicles under increasing concentrations. Robinson and Zana ${ }^{21}$ discussed that the dynamics of micelle-to-vesicle transformations could be very slow and often what is studied (from 1 second to days) is the evolution of vesicle structures. They recommended direct observation of the evolution of intermediate morphologies by cryo-transmission electron microscopy. In our AFM experiments, the time scale of minutes in the sample preparation was enough to develop micelles and polymersomes separately, but this duration was not enough for micelle-to-vesicle transformations. Moreover, at very low concentrations such as $13.24 \mathrm{nM}$ or $3 \times 10^{-5} \mathrm{~g} / \mathrm{L}$ (1,000-fold more dilute than the $\mathrm{CMC}$ of the copolymer), tests showed that the remaining stable particles must be small polymersomes $(<150 \mathrm{~nm}$ in size; Figure 8).

Previous studies indicate that polymersomes made from large amphiphilic diblock copolymers are more stable and much less water permeable compared to phospholipids 
Table I DLS results for particle size and polydispersity index of mPEG-OA nanocarriers

\begin{tabular}{|c|c|c|c|c|c|c|}
\hline & & \multicolumn{4}{|c|}{ Particle size $(\mathrm{nm})$} & \multirow{2}{*}{$\begin{array}{l}\text { Polydispersity } \\
\text { index }\end{array}$} \\
\hline & & Micelles & & Polymersomes & & \\
\hline \multicolumn{7}{|c|}{ Blank mPEG-OA } \\
\hline \multirow[t]{8}{*}{$0 \%$} & Fresh & $16.75 \pm 4$ & & $51.85 \pm 15.6$ & $301 \pm 112$ & $0.47 \pm 0.07 \mid$ \\
\hline & $22 \mu \mathrm{M}$ & $(56.9 \%)$ & & $(36.6 \%)$ & $(6.6 \%)$ & \\
\hline & Fresh & & $44 \pm 23.8$ & & $290 \pm 136$ & $0.418 \pm 0.06$ \\
\hline & $66 \mu \mathrm{M}$ & & $(74 \%)$ & & $(26 \%)$ & \\
\hline & Fresh & & $32.4 \pm 41.8$ & & & $0.47 \pm 0.05$ \\
\hline & $440 \mu \mathrm{M}$ & & $(99.4 \%)$ & & & \\
\hline & After I week & & & $84.4 \pm 25.7$ & & $0.182 \pm 0.07$ \\
\hline & & & & $(100 \%)$ & & \\
\hline \multicolumn{7}{|c|}{ Curcumin encapsulated in mPEG-OA nanocarriers $(0.05 \mathrm{mg} / \mathrm{mL})$} \\
\hline \multirow[t]{4}{*}{$5 \%$} & Fresh & $18.1 \pm 4$ & & $72.1 \pm 30.8$ & & $0.38 \pm 0.06$ \\
\hline & & $(76.3 \%)$ & & $(23.7 \%)$ & & \\
\hline & After I week & & & $85.9 \pm 33$ & & $0.1 \pm 0.02$ \\
\hline & & & & $(100 \%)$ & & \\
\hline \multirow[t]{4}{*}{$10 \%$} & Fresh & $17.5 \pm 3.7$ & & $95.7 \pm 45.2$ & & $0.33 \pm 0.05$ \\
\hline & & $(87.2 \%)$ & & $(12.7 \%)$ & & \\
\hline & After I week & & & $117 \pm 47$ & & $0.13 \mid \pm 0.05$ \\
\hline & & & & $(100 \%)$ & & \\
\hline \multirow[t]{8}{*}{$15 \%$} & Fresh & $19.6 \pm 5.5$ & & $105.5 \pm 70.2$ & & $0.332 \pm 0.03$ \\
\hline & $22 \mu \mathrm{M}$ & $(49.5 \%)$ & & $(50.5 \%)$ & & \\
\hline & Fresh & & & $154 \pm 93$ & & $0.21 \pm 0.02$ \\
\hline & $0.44 \mu \mathrm{M}$ & & & $(100 \%)$ & & \\
\hline & Fresh & & & $|3| \pm 85.5$ & & \\
\hline & $0.044 \mu \mathrm{M}$ & & & $(100 \%)$ & & \\
\hline & After I week & & & $129 \pm 58$ & & $0.196 \pm 0.037$ \\
\hline & & & & $(100 \%)$ & & \\
\hline \multirow[t]{4}{*}{$20 \%$} & Fresh & $22.7 \pm 6.8$ & & $133 \pm 54$ & & $0.4 I \pm 0.2$ \\
\hline & & (84.2\%) & & $(15.8 \%)$ & & \\
\hline & After I week & & & $132 \pm 62$ & & $0.13 \mid \pm 0.06$ \\
\hline & & & & $(100 \%)$ & & \\
\hline \multirow[t]{4}{*}{$25 \%$} & Fresh & & & $69.2 \pm 27.5$ & $319 \pm 135$ & $0.57 \pm 0.07$ \\
\hline & & & & (58.7\%) & $(41.3 \%)$ & \\
\hline & After I week & & & $109 \pm 26.7$ & & $0.249 \pm 0.06$ \\
\hline & & & & $(100 \%)$ & & \\
\hline
\end{tabular}

Notes: Size is measured as hydrodynamic diameter. All data are shown as volume $\%$ versus mean size \pm standard deviation $(\mathrm{n} \geq 3$ ).

Abbreviations: DLS, dynamic light scattering; mPEG-OA, monomethoxy poly(ethylene glycol)-oleate; $n$, number.

in liposomes, ${ }^{23}$ and the shape and formation of micelle or polymersome vesicles are commonly determined by the relative hydrophobicity and geometry of the polymer blocks. ${ }^{9,24,25}$ Discher and Ahmed $^{11}$ described a starting point rule that says when the hydrophilic segment of a block copolymer constitutes more than $50 \%$ of the whole block, copolymer monoblocks tend to form conical structures, and spherical micelles can probably be expected in the solution. Additionally, the report briefly mentioned that sometimes micelles and polymersomes can be observed together in a dispersion. In the case of mPEG-OA, with a hydrophilic part constituting approximately $85 \%$, the results of these tests proved the coexistence of both forms at the $\mathrm{CMC}$; furthermore, the micelle/polymersome ratio was concentration dependent. For this diblock copolymer with a small hydrophobic portion, the aforementioned rule expressed by Discher and $\mathrm{Ahmad}^{11}$ is applicable only at concentrations higher than the $\mathrm{CMC}$, where the micellar form is predominant (Figure 7A). However, at concentrations lower than $\mathrm{CMC}$, the polymersome ratio begins to increase until they are the dominant form, for example at concentrations between $13.24 \times 10^{-1} \mu \mathrm{M}$ and $13.24 \times 10^{-3} \mu \mathrm{M}$ (or $10^{-3} \mathrm{~g} / \mathrm{L}$ and $10^{-5} \mathrm{~g} / \mathrm{L}$; Figure $7 \mathrm{~B}$ ).

Besides concentration, the polymersome ratio is also dependent on the storage time. For example, for the samples of $22 \mu \mathrm{M}$ or $0.05 \mathrm{~g} / \mathrm{L}$, the volume of particles increased after 1 week of storage at room temperature (Figure 6 and Table 1). In this case, the micellar population disappeared 
A

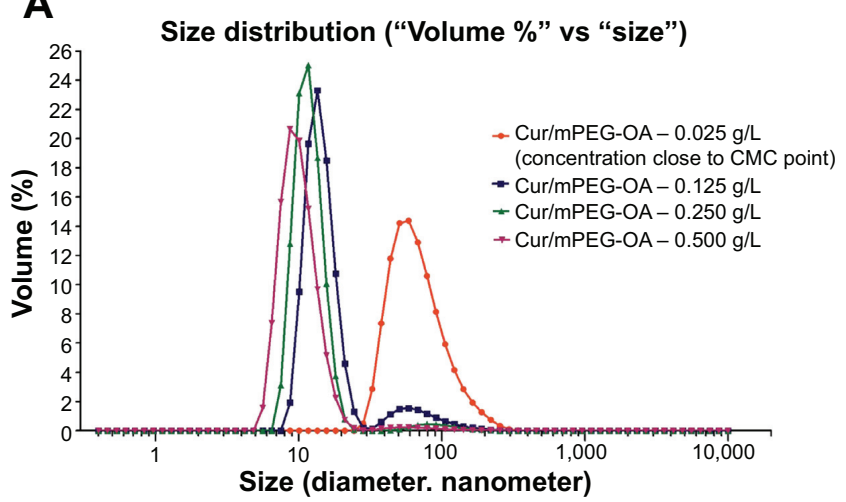

B

\section{Size distribution ("Volume \%” vs "size”)}

Figure 7 DLS diagram of the effect of concentration on mPEG-OA nanocarrier size and polydispersity.

Notes: (A) At concentrations higher than the CMC where the micellar form is predominant; and (B) at concentrations lower than the CMC where the polymersome ratio begins to increase until polymersomes become the dominant form.

Abbreviations: Cur/mPEG-OA, curcumin/monomethoxy poly(ethylene glycol)-oleate; DLS, dynamic light scattering; mPEG-OA, monomethoxy poly(ethylene glycol)-oleate; CMC, critical micelle concentration.

and only polymersomes were formed. Therefore, in contrast to previous reports, it seems that according to the concentration and storage time, the small hydrophobic part of the diblock copolymers can mainly develop into polymersomes.

\section{Stability of nanostructures}

After 1 week at room temperature, the monodispersity of mPEG-OA nanocarriers increased, as the PDI of samples decreased from $0.47 \pm 0.071$ to $0.182 \pm 0.07$ (Figure 6 and Table 1). This increase in monodispersity indicates the stability of the mPEG-OA nanocarriers. Moreover, when the lyophilized samples were redissolved in water by manual shaking, the micelle/polymersome size distributions were not significantly changed from those of the freshly prepared samples (as measured by DLS). Except for some exceptional curcumin precipitation at DL levels higher than $6 \%$ within a few days,

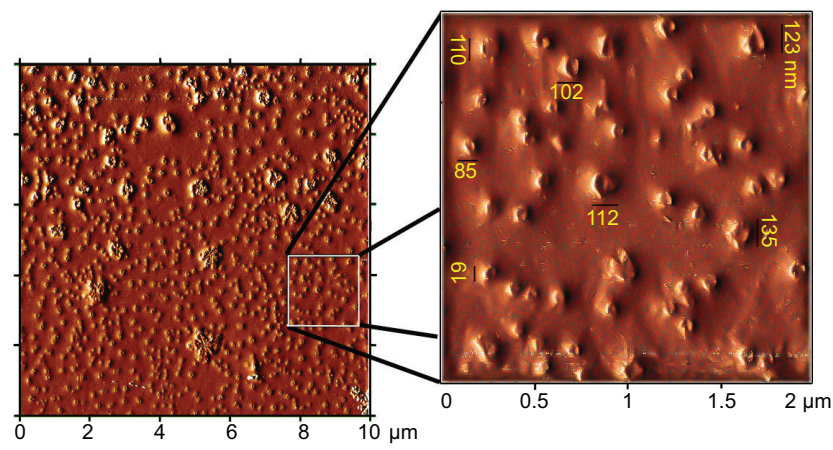

Figure $8 \mathrm{AFM}$ analysis of Cur/mPEG-OA performed at I,000-fold dilution compared to the CMC.

Notes: Cur/mPEG-OA nanocarrier $\left(13.24 \mathrm{nM}\right.$ or $\left.3 \times 10^{-5} \mathrm{~g} / \mathrm{L}\right)$ redissolved after freezedrying. Most of Cur/mPEG-OA nanoparticles are smaller than $150 \mathrm{~nm}$ in diameter. Abbreviations: AFM, atomic force microscopy; Cur/mPEG-OA, curcumin/monomethoxy poly(ethylene glycol)-oleate; CMC, critical micelle concentration.
Cur/mPEG-OA nanocarriers were quite stable and transparent even after 10 months of storage at $4^{\circ} \mathrm{C}$ (Figure 9).

\section{Cell toxicity}

According to the MTT assay results for U87MG cells, the half maximal inhibitory concentration $\left(\mathrm{IC}_{50}\right)$ of the free curcumin solution was $48 \mu \mathrm{M}$, whereas the $\mathrm{IC}_{50}$ values for curcuminloaded mPEG-OA at 24 hours and 48 hours posttreatment were $24 \mu \mathrm{M}$ and $15.5 \mu \mathrm{M}$, respectively (Figure 10A). No significant toxicity was observed for void mPEG-OA nanocarriers even at a carrier concentration of $50 \mu \mathrm{M}$. These findings indicate that the encapsulation of curcumin within the mPEG-OA nanocarriers significantly increased the anticancer effect of curcumin $(P<0.05$; Figure 10). These results are in accordance with the reported cell toxicities of dendrosomeencapsulated curcumin. ${ }^{13}$ The higher level of toxicity of curcumin nanocarriers in our study could be attributed to the higher cellular internalization of encapsulated curcumin through mechanisms such as endocytosis. Interestingly, Sahu et $\mathrm{al}^{14}$ reported a similar cytotoxicity for a block copolymer assembly containing curcumin. They reported $\mathrm{IC}_{50}$ values of $15.58 \mu \mathrm{M}$ and $14.32 \mu \mathrm{M}$ for mPEG-palmitate-encapsulated curcumin and free curcumin, respectively, against HeLa cells. Consequently, in comparison with our results, it seems that while HeLa cells are more sensitive to free curcumin, both U87MG and HeLa cells exhibit almost the same sensitivity to curcumin nanocapsules at 48 hours posttreatment.

Based on the results of the cell toxicity evaluations, the $\mathrm{IC}_{50}$ values of curcumin-loaded mPEG-OA were greater than the CMC. Therefore, it seems that only when the micelles develop does the anticancer effect become significant. This may indicate that the micelles are more effective 


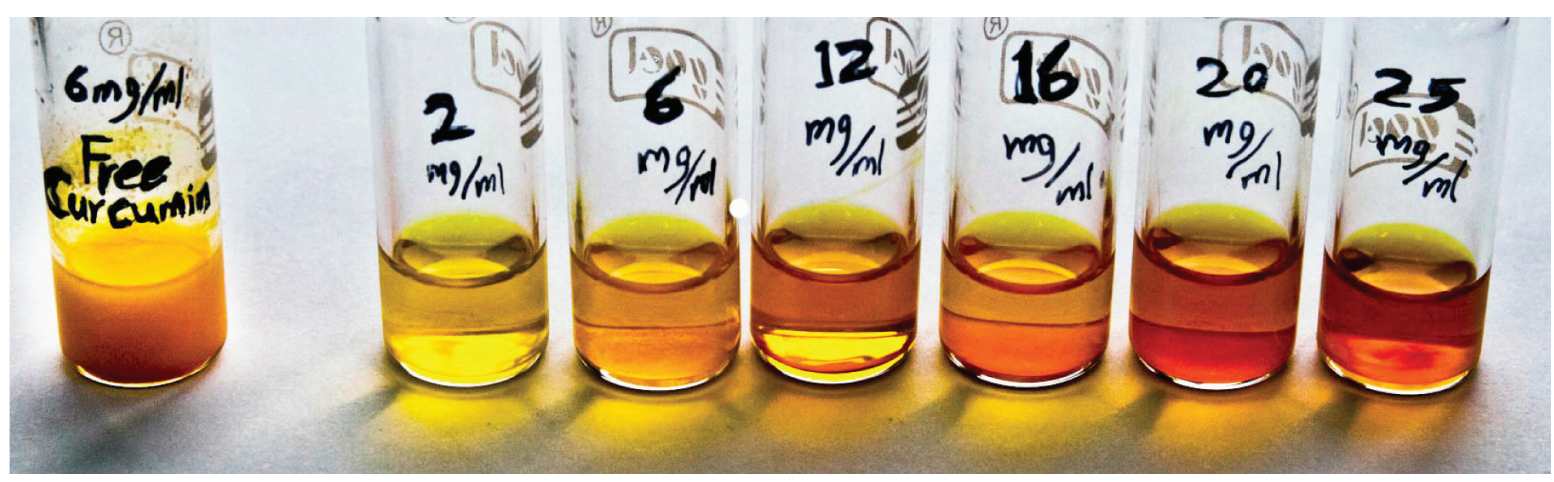

Figure $9 \mathrm{Cur} / \mathrm{mPEG}-\mathrm{OA}$ nanocarrier transparency over time.

Notes: mPEG-OA nanocarrier remained transparent after 300 days of storage at $4^{\circ} \mathrm{C}$, although loading efficiencies higher than $6 \%$ resulted in some curcumin precipitation in the prepared formulations.

Abbreviations: Cur/mPEG-OA, curcumin/monomethoxy poly(ethylene glycol)-oleate; mPEG-OA, monomethoxy poly(ethylene glycol)-oleate.

than polymersomes in terms of biological activity of the mPEG-OA delivery system. As shown in Figure 10, the viability curve at 48 hours of treatment surpassed that at 24 hours with a concentration of $25 \mu \mathrm{M}$ or higher. It is not clear why this happens, but we assume that over an extended exposure period, the cancer cells can become slightly resistant to the drug and can adapt to the toxic situation, thus showing better survival and proliferation. Another potential reason is related to the stability of the curcumin within this time period. As indicated in a previous study, ${ }^{26}$ curcumin is an unstable molecule that can be degraded within hours to days, depending on the medium in which it is dissolved. Wang et $\mathrm{al}^{26}$ showed that about $90 \%$ of curcumin degrades within 30 minutes in a serum-free medium $\left(\mathrm{pH} 7.2,37^{\circ} \mathrm{C}\right)$ and about $50 \%$ degrades within 8 hours in a cell culture medium containing $10 \%$ serum $\left(\mathrm{pH} 7.2,37^{\circ} \mathrm{C}\right)$. Therefore, curcumin degradation could be responsible for the lower cytotoxicity at the later exposure time. However, further evaluations are needed to reach a cogent conclusion on this topic.

The mPEG-OA carrier was not toxic to normal fibroblastic cells. According to Figure 10B, at an effective dose for anticancer activity (below $25 \mu \mathrm{M}$ ) and even at $50 \mu \mathrm{M}$, curcumin and void mPEG-OA carrier were not significantly toxic to normal human fibroblastic cells (HFSF-PI3). These results show that the mPEG-OA carrier has very low toxicity to normal cells, and curcumin encapsulated in mPEG-OA was specifically toxic to U87MG cancer cells. These findings are in accordance with previous studies showing that curcumin kills tumor cells selectively. ${ }^{27}$

\section{Fluorescence microscopy and cell-cycle analysis}

Fluorescence microscopy showed that mPEG-OA nanocarriers significantly improved the internalization of curcumin in
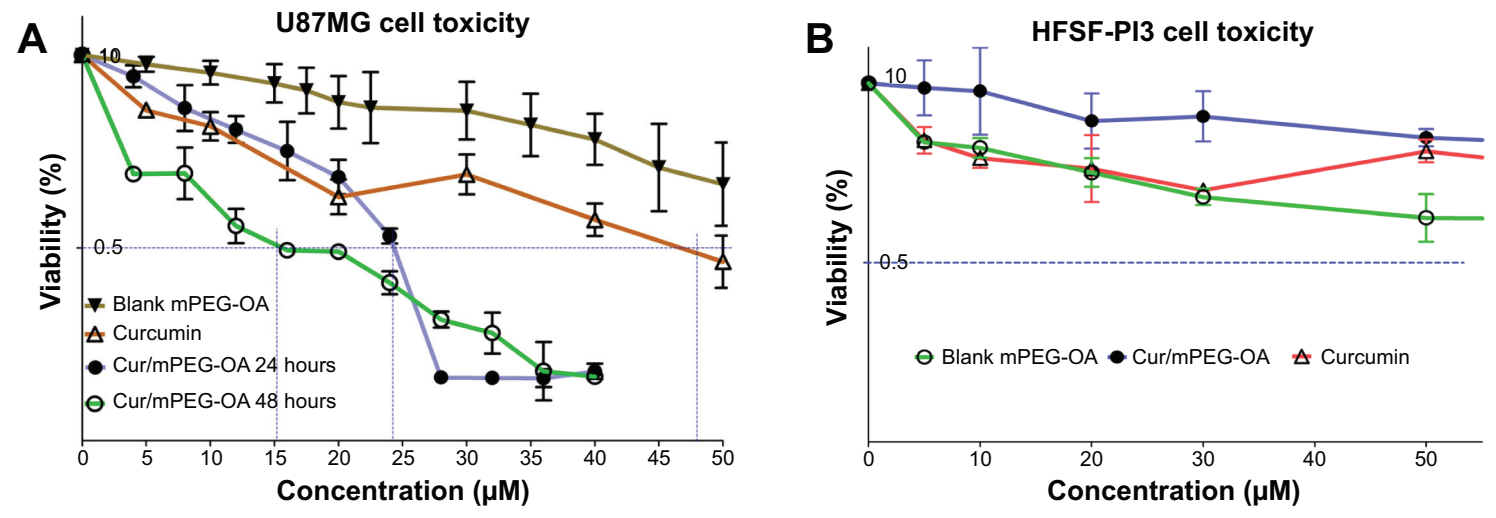

Figure 10 Cytotoxicity of Cur/mPEG-OA nanocarriers.

Notes: (A) U87MG cancer cell line. Cells were treated by different concentrations of free or encapsulated curcumin and evaluated at 24 hours and 48 hours after the treatment. (B) Normal human fibroblastic cells (HFSF-PI3). At an effective dose for anticancer effects (below $25 \mu \mathrm{M}$ ) and even at $50 \mu \mathrm{M}$, curcumin and blank mPEG-OA carrier were not significantly toxic to normal human fibroblastic cells (HFSF-PI3). The surviving cells were indirectly measured by MTT assay. The results are shown as the mean \pm SD of three replicates, as a percentage relative to the control.

Abbreviations: Cur/mPEG-OA, curcumin/monomethoxy poly(ethylene glycol)-oleate; mPEG-OA, monomethoxy poly(ethylene glycol)-oleate; MTT, 3-(4,5-dimethylthiazol2-yl)-2,5-diphenyltetrazolium bromide; SD, standard deviation. 
U87MG cancer cells (Figure 11). The effects of curcumin and Cur/mPEG-OA on cell-cycle distribution were evaluated by flow cytometry after cells were stained with PI. To gain further insight into the mechanism of the growth inhibition of Cur/ mPEG-OA, U87MG cells were treated with concentrations close to the $\mathrm{IC}_{50}(22 \mu \mathrm{M})$ determined by the MTT assay. It has been reported that curcumin enhances expression of tumor cyclin-dependent kinase inhibitors, p21 and p27, as well as the tumor suppressor protein, p53. Moreover, it can induce $\mathrm{G} 0 / \mathrm{G} 1$ and/or G2/M phase cell-cycle arrest in multiple human tumor cell lines. ${ }^{27}$ Additionally, for U87MG cells, some reports have noted cell accumulation in the sub-G1 cell-cycle phase. ${ }^{27}$ According to our previous study, ${ }^{13}$ with respect to treatment with curcumin encapsulated in dendrosomes (a self-assembling structure similar to the mPEG-OA of the present study), the cell population in the sub-G1 phase was significantly increased $(P<0.05)$ in comparison to the control. This has also been reconfirmed by the present study in which Cur/mPEG-OA (22 $\mu \mathrm{M}$ curcumin) led to sub-G1 cell-cycle arrest $(5.35 \% \pm 0.84 \%)$, more so than $30 \mu \mathrm{M}$ free curcumin $(3.56 \% \pm 0.07 \%)$ or untreated control $(1.55 \% \pm 0.55 \%)$ in U87MG cells (Table 2). The difference between the sub-G1 arrested cell populations with Cur/mPEG-OA and the untreated control was significant $(P<0.05)$. Additionally, similar to previous findings on curcumin, ${ }^{27,28}$ treating cells with Cur/ mPEG-OA can cause a significant increase in the cell population in the $\mathrm{G} 2 / \mathrm{M}$ phase. Cur/mPEG-OA (22 $\mu \mathrm{M}$ curcumin) led to $\mathrm{G} 2 / \mathrm{M}$ phase arrest $(32.23 \% \pm 0.8 \%)$, obviously more so than $30 \mu \mathrm{M}$ free curcumin $(18 \% \pm 0.56 \%)$ or untreated control $(21.22 \% \pm 1.83 \%)$ in U87MG cells (Table 2$)$. The difference between the $\mathrm{G} 2 / \mathrm{M}$ phase-arrested cell populations with $\mathrm{Cur} /$ $\mathrm{mPEG}-\mathrm{OA}$ and untreated control was significant $(P<0.05)$.

\section{Cur/mPEG-OA induces apoptosis in U87MG cancer cells}

The Annexin-V-FLUOS and PI staining assay is a test that differentiates early apoptosis and necrosis (secondary apoptotic cells). The role of curcumin in inducing apoptosis has been investigated in numerous studies, and its potential to activate different pathways related to apoptosis has been demonstrated. ${ }^{29,30}$ In the present study, U87MG cells were exposed to different concentrations of curcumin $(1 \mu \mathrm{M}, 2.5 \mu \mathrm{M}, 5 \mu \mathrm{M}, 10 \mu \mathrm{M}, 20 \mu \mathrm{M}$, and $30 \mu \mathrm{M}$ of curcumin encapsulated in mPEG-OA) for 24 hours. As shown in Figure 12, Cur/mPEG-OA induced apoptosis in U87MG cells in a concentration-dependent behavior. The percentages of early apoptotic cells after 24 hours of treatment with $1 \mu \mathrm{M}, 2.5 \mu \mathrm{M}, 5 \mu \mathrm{M}, 10 \mu \mathrm{M}, 20 \mu \mathrm{M}$, or
$30 \mu \mathrm{M}$ curcumin (Cur/mPEG-OA) were determined to be $9.5 \% \pm 0.03 \%, 10.5 \% \pm 0.04 \%, 10.81 \% \pm 0.5 \%, 12.07 \% \pm 1 \%$, $44.53 \% \pm 2 \%$, and $28.73 \% \pm 1.5 \%$, respectively. These results are in accordance with those of our previous dendrosome research, ${ }^{13}$ which showed apoptosis induction in a time- and dose-dependent manner. Additionally, although apoptosis can be observed below the $\mathrm{IC}_{50}$, it seems that there are no significant differences between treatments below $10 \mu \mathrm{M}$ of curcumin (Cur/mPEG-OA). However, treatments with the higher concentrations, for example $20 \mu \mathrm{M}$ or $30 \mu \mathrm{M}$, of which the latter is higher than the $\mathrm{IC}_{50}(24 \mu \mathrm{M})$, significantly induce apoptosis. It should be noted that treatment with $30 \mu \mathrm{M}$ curcumin caused early apoptosis to be changed to late apoptosis (Figure 12). Increasing the curcumin concentration from $20 \mu \mathrm{M}$ to $30 \mu \mathrm{M}$ obviously induced late apoptosis in the cells. At the $20 \mu \mathrm{M}$ concentration, $44.53 \% \pm 2 \%$ and $4.21 \% \pm 1.5 \%$ of the cell populations were in early and late apoptosis, respectively, whereas at $30 \mu \mathrm{M}$, the percentages changed to $28.73 \% \pm 3.8 \%$ and $40.12 \% \pm 4.5 \%$, respectively. Interestingly, similar to the MTT assay results, blank mPEG-OA at $50 \mu \mathrm{M}$ had no cytotoxic effect on the cells and, therefore, no necrosis or apoptosis was observed following this treatment (Figure 12). Finally, with no necrosis-inducing effect and a structure similar to the dendrosome structures, ${ }^{13}$ it seems that this mPEG-OA formulation can be considered a safe nanocarrier for curcumin delivery to cancer cells.

\section{Conclusion}

This research demonstrates that micelles and polymersomes coexist even at very high ratios $(f \approx 85 \%)$ of hydrophilic parts to the total mass of copolymer blocks. It was shown in this study that micelles and polymersomes can form simultaneously from amphiphilic block copolymers, and the proportion of micelle/polymersome formation depends on the concentration of the block copolymer used. A higher concentration increases the number of micelles, and a lower concentration results in the formation of more favorable and thermodynamically stable polymersomes. It remains unclear whether the mPEG-OA polymersomes have any significant biological importance. The results for cell toxicity implied that micelles may be primarily responsible for the anticancer effect of the delivery system and were probably more important than polymersomes in mPEG-OA structures. However, new dendrosome structure modifications, such as using $\mathrm{mPEG}$ instead of PEG and a higher PEG molecular weight $(2,000$ $\mathrm{Da}$ ) instead of a low-molecular weight (500 Da), changed the anticancer properties of the curcumin cargo in favor of more selective cancer cell toxicity. Finally, with no necrotic 


\section{U87MG cancer cell line (fluorescence microscopy)}


Figure I I Fluorescence microscopy images of Cur/mPEG-OA nanocarriers.

Notes: Visible light (left column) and fluorescence (right column) images of Cur/mPEG-OA nanocarriers. Each pair of the left and right image is the same section of the cells pictured at the similar time points. Images show that free curcumin (solubilized with $1 \%$ methanol) and Cur/mPEG-OA (curcumin encapsulated) nanocarriers enter the U87MG cancer cells after 4 hours.

Abbreviation: Cur/mPEG-OA, curcumin/monomethoxy poly(ethylene glycol)-oleate. 
Table 2 Cell-cycle distribution in UM87MG cells (after 24 hours)

\begin{tabular}{lllll}
\hline & Sub-G0/G I & GI & S & G2/M \\
\hline 0 (control) & $1.55 \pm 0.55$ & $62.64 \pm 2.73$ & $9.91 \pm 0.42$ & $21.22 \pm 1.83$ \\
Free curcumin $(30 \mu \mathrm{M})$ & $3.56 \pm 0.07$ & $59.75 \pm 0.46$ & $15 \pm 0.33$ & $18 \pm 0.56$ \\
Cur/mPEG-OA $(22 \mu \mathrm{M}$ curcumin) & $5.35 \pm 0.84^{*}$ & $46.47 \pm 1.96$ & $8.9 \pm 0.26$ & $32.23 \pm 0.8^{*}$ \\
\hline
\end{tabular}

Notes: Data are shown as the mean percentages \pm standard deviation. *Different from control, $P<0.05$.

Abbreviation: Cur/mPEG-OA, curcumin/monomethoxy poly(ethylene glycol)-oleate.

effect on the cells (as shown by Annexin/PI evaluation), the mPEG-OA formulation can be considered a safe nanocarrier for the delivery of curcumin and other small hydrophobic molecule drugs. Further studies are currently underway to determine the potential of the mPEG-OA formulation for the in vivo enhancement of the efficacy of curcumin.

\section{Acknowledgments}

This project was supported by grants from the Faculty of Biological Sciences, Tarbiat Modares University, Tehran, Iran and the INSF (www.insf.gov.ir). We also acknowledge financial support from the Zanjan University of Medical Sciences for this research. We would like to express our
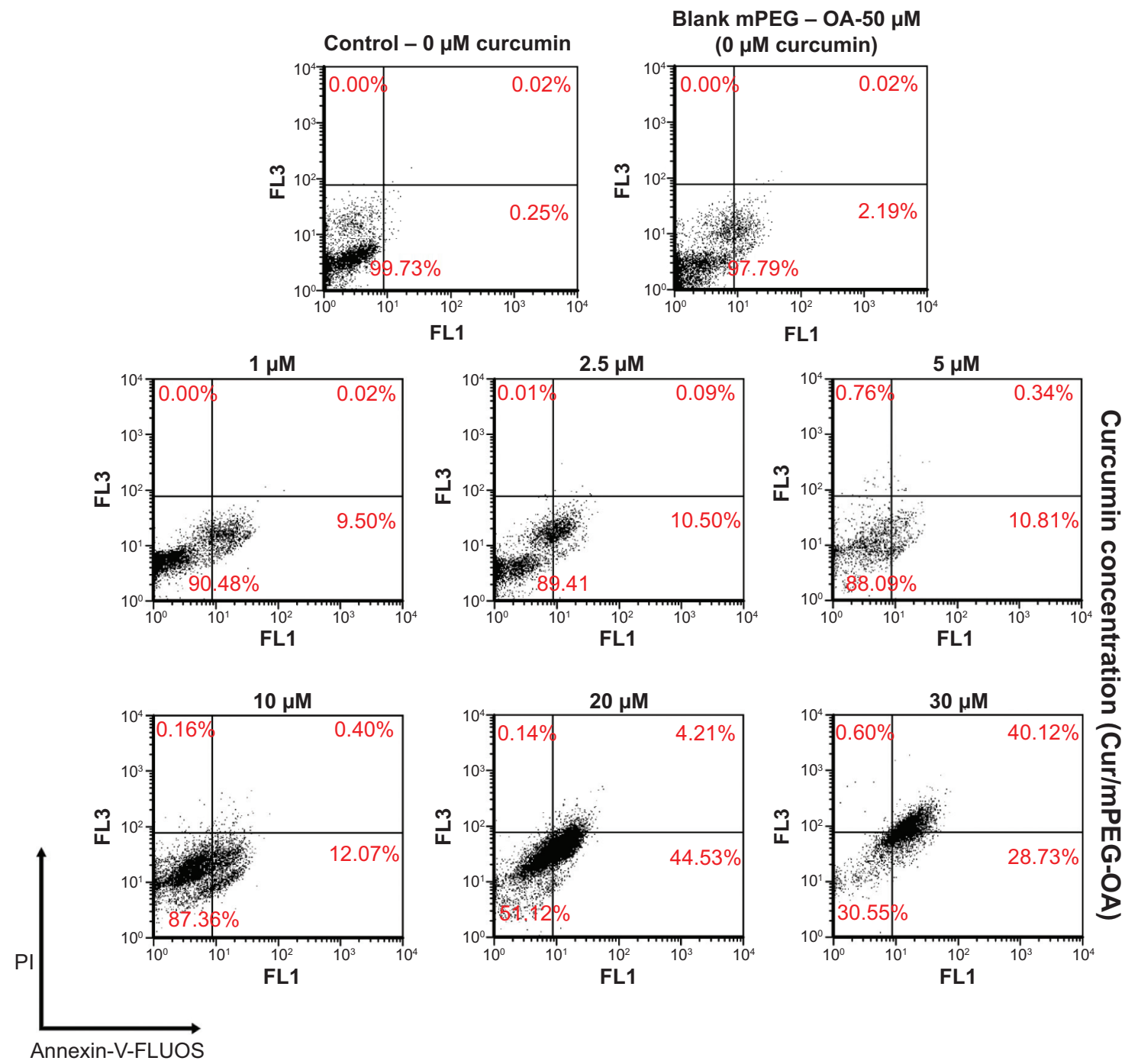

Figure 12 Cur/mPEG-OA-induced apoptosis or necrosis according to Annexin-V-FLUOS/PI staining in U87MG cells after 24 hours of incubation.

Notes: Viable cells (Annexin-V-/PI-), early apoptotic cells (Annexin-V+/PI-), necrotic cells (Annexin-V-/PI+), and necrotic cells or late apoptotic cells (Annexin-V+/PI+) are located in the lower left, lower right, upper left, and upper right quadrants, respectively. The numbers in each quadrant represent the percentages of cells. Abbreviations: mPEG-OA, monomethoxy poly(ethylene glycol)-oleate; Cur/mPEG-OA, curcumin/monomethoxy poly(ethylene glycol)-oleate; PI, propidium iodide. 
special thanks to Dr Majid Erfani-Moghadam for his generous assistance in manuscript preparation.

\section{Disclosure}

The authors report no conflicts of interest in this work.

\section{References}

1. Siegel R, Ma J, Zou Z, Jemal A. Cancer statistics, 2014. CA Cancer J Clin. 2014;64(1):9-29.

2. Yallapu MM, Jaggi M, Chauhan SC. Curcumin nanoformulations: a future nanomedicine for cancer. Drug Discov Today. 2012;17(1-2):71-80

3. Mimeault M, Batra SK. Potential applications of curcumin and its novel synthetic analogs and nanotechnology-based formulations in cancer prevention and therapy. Chin Med. 2011;6:31.

4. Hatcher H, Planalp R, Cho J, Torti FM, Torti SV. Curcumin: from ancient medicine to current clinical trials. Cell Mol Life Sci. 2008;65(11): 1631-1652.

5. Goel A, Kunnumakkara AB, Aggarwal BB. Curcumin as "Curecumin": from kitchen to clinic. Biochem Pharmacol. 2008;75(4):787-809.

6. Ma Z, Haddadi A, Molavi O, Lavasanifar A, Lai R, Samuel J. Micelles of poly(ethylene oxide)-b-poly(epsilon-caprolactone) as vehicles for the solubilization, stabilization, and controlled delivery of curcumin. J Biomed Mater Res A. 2008;86(2):300-310.

7. Xiong XB, Binkhathlan Z, Molavi O, Lavasanifar A. Amphiphilic block co-polymers: preparation and application in nanodrug and gene delivery. Acta Biomater. 2012;8(6):2017-2033.

8. Tong R, Cheng J. Anticancer polymeric nanomedicines. Polym Rev (Phila Pa). 2007;47:345-381.

9. Hamidi M, Shahbazi MA, Rostamizadeh K. Copolymers: efficient carriers for intelligent nanoparticulate drug targeting and gene therapy. Macromol Biosci. 2012;12(2):144-164.

10. Antonietti M, Förster S. Vesicles and liposomes: a self-assembly principle beyond lipids. Adv Mater. 2003;15(16):1323-1333.

11. Discher DE, Ahmed F. Polymersomes. Annu Rev Biomed Eng. 2006; 8:323-341.

12. Babaei E, Sadeghizadeh M, Hassan ZM, Feizi MA, Najafi F, Hashemi SM. Dendrosomal curcumin significantly suppresses cancer cell proliferation in vitro and in vivo. Int Immunopharmacol. 2012;12(1): 226-234.

13. Tahmasebi Mirgani M, Isacchi B, Sadeghizadeh M, et al. Dendrosomal curcumin nanoformulation downregulates pluripotency genes via miR-145 activation in U87MG glioblastoma cells. Int J Nanomedicine. 2014;9:403-417.

14. Sahu A, Bora U, Kasoju N, Goswami P. Synthesis of novel biodegradable and self-assembling methoxy poly(ethylene glycol)-palmitate nanocarrier for curcumin delivery to cancer cells. Acta Biomater. 2008;4(6):1752-1761.

15. Darvishi MH, Nomani A, Amini M, Shokrgozar MA, Dinarvand R. Novel biotinylated chitosan-graft-polyethyleneimine copolymer as a targeted non-viral vector for anti-EGF receptor siRNA delivery in cancer cells. Int J Pharm. 2013;456(2):408-416.
16. Gou M, Men K, Shi H, et al. Curcumin-loaded biodegradable polymeric micelles for colon cancer therapy in vitro and in vivo. Nanoscale. 2011;3(4):1558-1567.

17. Song L, Shen Y, Hou J, Lei L, Guo S, Qian C. Polymeric micelles for parenteral delivery of curcumin: Preparation, characterization and in vitro evaluation. Colloids Surf A Physicochem Eng Asp. 2011;390(1-3):25-32.

18. Vindeløv LL, Christensen IJ, Nissen NI. A detergent-trypsin method for the preparation of nuclei for flow cytometric DNA analysis. Cytometry. 1983;3(5):323-327.

19. Adams ML, Lavasanifar A, Kwon GS. Amphiphilic block copolymers for drug delivery. J Pharm Sci. 2003;92(7):1343-1355.

20. Pearson RT, Avila-Olias M, Joseph AS, Nyberg S, Battaglia G. Smart polymersomes: formation, characterisation and applications. In: Alvarez-Lorenzo C, Concheiro A, editors. Smart Materials for Drug Delivery. Vol 1. Cambridge, UK: Royal Society of Chemistry; 2013:179-207.

21. Robinson BR, Zana R. Dynamic processes in aqueous vesicle systems. In: Zana R, editor. Dynamics of Surfactant Self-Assemblies: Micelles, Microemulsions, Vesicles and Lyotropic Phases. Vol 125. New York, NY: CRC Press, Taylor \& Francis; 2005:299-338.

22. Zana R. Introduction to surfactants and surfactant self-assemblies. In: Zana R, editor. Dynamics of Surfactant Self-Assemblies: Micelles, Microemulsions, Vesicles and Lyotropic Phases. Vol 125. New York, NY: CRC Press, Taylor \& Francis; 2005:1-36.

23. Discher BM, Won YY, Ege DS, et al. Polymersomes: tough vesicles made from diblock copolymers. Science. 1999;284(5417):1143-1146.

24. Hillmyer MA, Bates FS. Synthesis and characterization of model polyalkane-poly(ethylene oxide) block copolymers. Macromolecules. 1996;29(22):6994-7002.

25. Levine DH, Ghoroghchian PP, Freudenberg J, et al. Polymersomes: a new multi-functional tool for cancer diagnosis and therapy. Methods. 2008;46(1):25-32.

26. Wang YJ, Pan MH, Cheng AL, et al. Stability of curcumin in buffer solutions and characterization of its degradation products. J Pharm Biomed Anal. 1997;15(12):1867-1876.

27. Ravindran J, Prasad S, Aggarwal BB. Curcumin and cancer cells: how many ways can curry kill tumor cells selectively? AAPS J. 2009;11(3):495-510.

28. Aoki H, Takada Y, Kondo S, Sawaya R, Aggarwal BB, Kondo Y. Evidence that curcumin suppresses the growth of malignant gliomas in vitro and in vivo through induction of autophagy: role of Akt and extracellular signal-regulated kinase signaling pathways. Mol Pharmacol. 2007;72(1):29-39.

29. Karmakar S, Banik NL, Patel SJ, Ray SK. Curcumin activated both receptor-mediated and mitochondria-mediated proteolytic pathways for apoptosis in human glioblastoma T98G cells. Neurosci Lett. 2006;407(1):53-58.

30. Karmakar S, Banik NL, Ray SK. Curcumin suppressed antiapoptotic signals and activated cysteine proteases for apoptosis in human malignant glioblastoma U87MG cells. Neurochem Res. 2007;32(12):2103-2113.
International Journal of Nanomedicine

\section{Publish your work in this journal}

The International Journal of Nanomedicine is an international, peerreviewed journal focusing on the application of nanotechnology in diagnostics, therapeutics, and drug delivery systems throughout the biomedical field. This journal is indexed on PubMed Central, MedLine, CAS, SciSearch ${ }^{\circledR}$, Current Contents ${ }^{\circledR} /$ Clinical Medicine,

\section{Dovepress}

Journal Citation Reports/Science Edition, EMBase, Scopus and the Elsevier Bibliographic databases. The manuscript management system is completely online and includes a very quick and fair peer-review system, which is all easy to use. Visit http://www.dovepress.com/ testimonials.php to read real quotes from published authors. 